1985-6

\title{
Construct Validation of the Self-Control Schedule
}

P. Scott Richards

Brigham Young University - Provo, scott_richards@byu.edu

Follow this and additional works at: https://scholarsarchive.byu.edu/facpub

Part of the Student Counseling and Personnel Services Commons

\section{Original Publication Citation}

Richards, P.S. (1985). Construct validation of the self-control schedule. Journal of Research in Personality, 19, 208-218.

\section{BYU ScholarsArchive Citation}

Richards, P. Scott, "Construct Validation of the Self-Control Schedule" (1985). Faculty Publications. 3873. https://scholarsarchive.byu.edu/facpub/3873 accepted for inclusion in Faculty Publications by an authorized administrator of BYU ScholarsArchive. For more information, please contact ellen_amatangelo@byu.edu. 


\title{
Construct Validation of the Self-Control Schedule
}

\author{
P. SCOTT RICHARDS \\ University of Minnesota
}

\begin{abstract}
The present paper describes an investigation of the construct validity of the English version of M. Rosenbaum's (1980, Behavior Therapy, 11, 109-121) SelfControl Schedule (SCS). A total of 121 Brigham Young University students took the SCS and several other measures. $t$ tests were conducted between the Brigham Young University student SCS means and the SCS means of samples from two midwestern universities. Pearson correlations between the SCS, the SCS subscales, Rotter's I-E scale, the Manifest Anxiety scale, and the Religious Orientation scale were computed. Reliability analyses were conducted on the SCS subscales. The results (a) provide additional normative data about the SCS, (b) further establish the comparability of the Hebrew and English versions of the SCS, (c) expand the nomological network and support the construct validity of the SCS, and (d) indicate that the SCS may have potential as a multidimensional instrument. 1985 Academic Press, Inc.
\end{abstract}

In response to the need to help people overcome problems such as drug addiction, smoking, crime, violence and aggression, alcoholism, sexual excesses and deviations, and obesity, many psychologists have become involved in research about self-control (e.g., Goldfried \& Merbaum, 1973; Kanfer, 1977; Thoresen \& Mahoney, 1974). As a result of these efforts, a number of theoretical models of self-regulation have been proposed and numerous self-control techniques and treatment programs have been developed (e.g., Jeffrey \& Berger, 1982; Kanfer, 1980; Karoly \& Kanfer, 1982; Meichenbaum, 1975).

Despite the large amount of theorizing and research about the nature of self-control, for many years the assessment of individual differences in self-control was given little attention in the literature. However, Ro-

This research was supported in part by a research grant from the Associated Students of Brigham Young University and the Department of Psychology at Brigham Young University. I am grateful to David J. Weiss, Mark L. Davison, and Judy Bartlett at the University of Minnesota for valuable suggestions annd comments and to Gary Scoville and Marcia Richards, who helped collect and analyze the data. The author is currently a Ph.D. student in the Department of Educational Psychology at the University of Minnesota. Requests for reprints should be sent to P. Scott Richards, Cooperative Learning-Mainstreaming Projects, 202 Pattee Hall, 150 Pillsbury Dr. S.E., Minneapolis, MN 55455. 
senbaum (1980a) has recently developed a potentially important selfreport measure, the Self-Control Schedule (SCS), in an effort to provide researchers with a way of assessing individual differences in the ability or tendency to utilize self-control techniques. Some evidence that the SCS is a reliable and valid instrument has been reported (Redden, Tucker, \& Young, 1983; Rosenbaum, 1980a, 1980b; Rosenbaum \& Rolnick, 1983); however, there are deficiencies in this data base that need to be overcome.

The first deficiency in the SCS data base is that most of the research has been done with the Hebrew version of the SCS on an Israeli population. Rosenbaum (1980a) has pointed out the need for more research to be done with the English version of the instrument on other populations. Such research would help establish the comparability (or lack of comparability) of the Hebrew and English versions of the SCS and would provide more normative data about the instrument.

The second deficiency in the data base, related to the first, is that not enough research has been done to adequately establish the nomological network of the SCS. One type of evidence which helps cstablish the nomological network of an instrument is theoretically meaningful correlations between the instrument and other variables (Betz \& Weiss, 1976; Cronbach \& Meehl, 1955). Considering that only a handful of studies have been published which examine the relationship between the SCS and other criterion variables, it is clear that more studies which do so need to be done.

The third deficiency in the data base is that not enough research exists to determine how useful the SCS is as a multidimensional instrument. Only one study has examined the dimensionality of the SCS. Redden et al. (1983) found that the SCS is composed of at least six factors; however, they concluded that "the factor structure . . . indicates a lack of a clear, strong factor structure" and cautioned that interpretation of the factors should "proceed tentatively" (pp. 84-85). Research examining the usefulness and meaning of the factors identified by Redden et al. (1983) should be done to help determine whether the SCS would be useful as a multidimensional instrument.

This study was designed to help overcome the above deficiencies in the SCS data base. Specifically, the first purpose of the study was to provide additional normative data about the English version of the SCS. To obtain this information, the SCS was administered to 121 Brigham Young University undergraduate students.

The second purpose of the study was to further establish the comparability of the Hebrew and English versions of the SCS. It was hypothesized that the correlation between the English versions of the SCS and Rotter's I-E scale (Rotter, 1966) would be comparable to the correlation Rosenbaum (1980a) found between the Hebrew versions of these instruments $(r(261)=-.40, p<.01)$. Confirmation of this hypothesis would 
provide some evidence that the Hebrew and English versions of the SCS are comparable.

The third purpose of the study was to further expand the nomological network of the SCS by examining the relationship between the SCS and measures of other constructs. It was hypothesized that the SCS would be significantly negatively correlated with the Manifest Anxiety scale (Taylor, 1953). Hall (1980) reported that self-control treatments have been effective in reducing anxiety and in treating anxiety-related problems; thus, it was felt that those who reported utilizing self-control techniques often would tend to experience less anxiety than those who reported utilizing self-control techniques less frequently. It was also hypothesized that the SCS would be significantly positively correlated with the Intrinsic scale, and negatively correlated with the Extrinsic scale, of the Religious Orientation scale (Allport \& Ross, 1967). A positive relationship between the Intrinsic scale and the SCS was expected because intrinsically religious people seek to live their religion (Allport \& Ross, 1967) and thus, it was theorized, would have a need to utilize self-control techniques to help keep their behavior in harmony with the standards of their church. A negative relationship between the Extrinsic scale and the SCS was expected because extrinsically religious people are less concerned about keeping their behavior in harmony with the standards of their church (Allport \& Ross, 1967) and would thus feel less of a need to utilize self-control techniques.

The fourth purpose of the study was to examine the usefulness of the SCS scales based on the factors identified by Redden et al. (1983) to help determine whether the SCS has promise as a multidimensional instrument. To shed light on this question, the internal consistency reliabilities (Cronbach, 1951) of the SCS scales and the correlations of the scales with the I-E scale (Rotter, 1966), the Manifest Anxiety scale (Taylor, 1953), the Religious Orientation scale (Allport \& Ross, 1967), and the other SCS scales were examined.

\section{METHOD}

\section{Subjects}

Sample 1. During the 1982 fall semester, 28 students in an introductory psychology class at Brigham Young University took the SCS. The subjects ranged in age from 18 to 25 years and had a mean age of 19.7 years. The subjects were 15 freshman, 5 sophomores, 5 juniors, and 0 seniors, and the class standing of 3 subjects was unknown. Sixteen subjects were females and 12 were males.

Sample 2. During the 1983 winter semester, 60 students in several undergraduate psychology classes at Brigham Young University took the SCS and the I-E scale (Rotter, 1966). The subjects ranged in age from 17 to 34 years and had a mean age of 21.4 years. Subjects were 14 freshman, 27 sophomores, 9 juniors, and 9 seniors, and the class standing of 1 subject was unknown. Thirty-five subjects were females and 25 were males.

Sample 3. During the 1983 spring term, 33 students in several undergraduate psychology classes at Brigham Young University took the SCS, the Manifest Anxiety scale (Taylor, 
1953), and the Religious Orientation scale (Allport \& Ross, 1967). The subjects ranged in age from 17 to 39 years and had a mean age of 21.3 years. Subjects were 12 freshman, 8 sophomores, 8 juniors, and 5 seniors. Twenty-one subjects were females and 12 were males.

\section{Procedure}

Subjects were recruited from undergraduate psychology classes and were offered extra class credit for participation. Interested students were asked to sign up for a 1-h period when they could come into the test administration room. When the subjects reported to the testing room, the test administrator informed the subjects what the general purpose of the study was and offered to provide more specific details about the purpose and results of the study after the study was completed.

The test administrator then gave the subjects a data sheet which asked them to provide demographic data such as age, sex, and year in school. Subjects then completed the SCS. After they completed the SCS, subjects in Sample 2 completed the I-E scale (Rotter, 1966) and subjects in Sample 3 completed the Manifest Anxiety scale (Taylor, 1953) and the Religious Orientation scale (Allport \& Ross, 1967). After subjects completed the instruments, the test administrator thanked them for participating and told them they could leave.

\section{Instruments}

Rosenbaum's (1980a) Self-Control Schedule is a self-report instrument which was developed to "assess the tendencies of individuals to apply self-management methods to the solution of common behavioral problems" (p. 110). The instrument is composed of 36 items which describe various self-control behaviors or strategies. Respondents are asked to indicate on a 6-point Likert scale the degree to which each item is characteristic of them. Rosenbaum (1980a) has reported a test-retest reliability (over 4 weeks) of $.86(p<.01)$ and internal consistency reliabilities ranging from .78 to .84 for the SCS. In addition, preliminary evidence supporting the construct validity of the SCS has been reported (Redden et al., 1983; Rosenbaum, 1980a, 1980b; Rosenbaum \& Rolnick, 1983).

Rotter's Locus of Control (I-E) scale (Rotter, 1966) measures the extent to which one believes that reinforcements are a function of one's behavior (internal locus of control) or a function of fate or other forces outside of one's control (external locus of control). The internal consistency reliability of the I-E scale ranges from .65 to .79 depending upon the statistical method and sample used (Rotter, 1966). The test-retest reliability of the I-E scale ranges from .49 to .83 depending upon the sample used and the length of time between testings (Rotter, 1966). Considerable evidence supporting the construct validity of the IE scale was reported by Rotter (1966) when the scale was published and a large amount of research since that time has been reported which has further established the validity of the I-E scale (e.g., Rotter, 1975).

The Manifest Anxiety scale (Taylor, 1953) measures the degree of anxiety people are experiencing in their lives. Taylor (1953) reported a test-retest reliability of .82 for the scale when the time between testings was 5 months and .89 when the time between testings was 3 weeks. Considerable evidence has also been published that supports the validity of the Manifest Anxiety scale (e.g., Taylor, 1956).

The Religious Orientation scale measures people's religious orientation (Allport \& Ross, 1967). People who "use their religion for their own ends" are considered extrinsically oriented and people who internalize and live their religion are considered intrinsically oriented (Allport \& Ross, 1967, p. 434). Item-to-subscale correlations ranging from .18 to .58 have been reported for the Religious Orientation scale (Allport \& Ross, 1967), and a substantial amount of research exists which supports the construct validity of the instrument (e.g., Donahue, 1985). 


\section{Analyses}

Four types of analyses were conducted. First, a one-way ANOVA was conducted to determine if the SCS means of the three samples differed significantly. Second, a $t$ test was conducted to determine if the SCS scores of the females differed significantly from those of the males, and four $t$ tests were conducted to determine if the total male and total female means of the Brigham Young University students were significantly higher than the male and female SCS means reported for other English-speaking university students (Redden et al., 1983; Rosenbaum, 1980a). Third, Pearson correlations were computed to determine the relationship between the SCS, the SCS subscales, and the I-E scale, the Manifest Anxiety scale, and the Intrinsic and Extrinsic scales of the Religious Orientation scale. Fourth, after combining the data from Samples 1,2, and 3, reliability analyses (Cronbach, 1951) were conducted to determine the internal consistency of the SCS subscales. For comparison's sake, the reliabilities of the SCS scales were calculated three times: first, using all 121 subjects for the analyses; second, using only male subjects; and third, using only female subjects.

\section{RESULTS}

The means for males in Samples 1, 2, and 3 were $32.6(S D=14.2)$, $38.2(S D=15.7)$, and $43.6(S D=14.9)$, respectively, and for females $29.9(S D=19.2), 37.1(S D=28.3)$, and $40.7(S D=17.6)$. The total male mean (Samples 1-3 combined) was $38.1(S D=15.4)$ and the total female mean was $36.5(S D=23.8)$. A one-way ANOVA revealed that the SCS scores of the three samples (males/females combined) did not differ significantly $F(2,118)=2.08, p=.13$, and a $t$ test revealed that the SCS means of the males and females did not differ significantly, $t(119)=.45, p=.65$.

In Table 1 it can be seen that the SCS means for the Brigham Young University students were higher than the SCS means reported by Rosenbaum (1980a) and Redden et al. (1983) for other English-speaking university students. $t$ tests revealed that the Brigham Young University males scored significantly higher on the SCS than University of Minnesota males, $t(82)=3.04, p<.005$, and higher than males in the Redden

TABLE 1

Self-Control Schedule Means and Standard Deviations

\begin{tabular}{|c|c|c|c|c|c|c|}
\hline \multirow[b]{2}{*}{ Study } & \multicolumn{3}{|c|}{ Male } & \multicolumn{3}{|c|}{ Female } \\
\hline & $n$ & Mean & $S D$ & $n$ & Mean & $S D$ \\
\hline \multicolumn{7}{|l|}{ Richards (1985) } \\
\hline Sample 1 & 12 & 32.6 & 14.2 & 16 & 29.9 & 19.2 \\
\hline Sample 2 & 25 & 38.2 & 15.7 & 35 & 37.1 & 28.3 \\
\hline Sample 3 & 12 & 43.6 & 14.9 & 21 & 40.7 & 17.6 \\
\hline Total & 49 & 38.1 & 15.4 & 72 & 36.5 & 23.8 \\
\hline Rosenbaum (1980a) & 35 & 25.9 & 20.6 & 76 & 27.5 & 20.6 \\
\hline $\begin{array}{l}\text { Redden, Tucker, \& Young } \\
\text { (1983) }\end{array}$ & 388 & 22.0 & 21.6 & 596 & 29.9 & 22.3 \\
\hline
\end{tabular}


et al. (1983) study, $t(435)=5.69, p<.001 . t$ tests also revealed that the Brigham Young University females scored significantly higher on the SCS than University of Minnesota females, $t(146)=2.47, p<.01$, and higher than females in the Redden et al. (1983) study, $t(666)=2.32$, $p<.025$.

The Pearson correlation between the SCS and the I-E scale (Rotter, 1966) was statistically significant, $r(58)=-.37, p=.002$. This confirmed the hypothesis that the correlation between the English versions of the SCS and the I-E scale would be comparable to the correlation Rosenbaum (1980a) found between the Hebrew versions of these instruments, $r(260)=$ $-.40, p<.01$.

The Pearson correlation between the SCS and the Manifest Anxiety scale was statistically significant, $r(31)=-.56, p=.001$, as was the correlation between the SCS and the Intrinsic scale of the Religious Orientation scale, $r(31)=.38, p=.015$. The SCS was not significantly correlated with the Extrinsic scale of the Religious Orientation scale, $r(31)=-.19, p=.15$. Thus, the hypotheses that the SCS would be significantly negatively correlated with the Manifest Anxiety scale and significantly positively correlated with the Intrinsic scale of the Religious Orientation scale were substantiated. The hypothesis that the SCS and the Extrinsic scale of the Religious Orientation scale would be significantly negatively correlated was not confirmed.

In Table 2 the results of the reliability analyses on the SCS scales based on the factors identified by Redden et al. (1983) are presented. As can be seen, when the total sample was used for the analyses, the Cronbach $\alpha$ 's of four scales were .70 or greater, the $\alpha$ 's of three scales approached .70, and the $\alpha$ of one scale was well below .70. Two scales which only had two items each (self-efficacy and pain control) had interitem correlations of $.51(p=.001)$ and $.86(p=.001)$.

When only males were used in the reliability analyses, the $\alpha$ 's of two scales were .70 , the $\alpha$ 's of two scales approached .70 , and the $\alpha$ 's of four scales were well below .70. The interitem correlations of the selfefficacy and pain control scales were $.44(p=.001)$ and $.80(p=.001)$, respectively.

When only females were used in the reliability analyses, the Cronbach $\alpha$ 's of six scales were .70 or greater and the $\alpha$ 's of two scales approached .70. The interitem correlations of the self-efficacy and pain control scales were $.56(p=.001)$ and $.90(p=.001)$, respectively.

In Table 3 it can be seen that the I-E scale was significantly negatively correlated with 7 SCS scales and not significantly correlated with 3 scales. The Manifest Anxiety scale was significantly negatively correlated with 4 SCS scales and not significantly correlated with 6 scales. The Intrinsic scale of the Religious Orientation scale was significantly positively correlated with 3 SCS scales and not significantly correlated with 7 scales. 
TABLE 2

Reliability of the Self-Control Schedule Scales

\begin{tabular}{|c|c|c|c|c|}
\hline & Items & $\begin{array}{c}\alpha \text { 's for } \\
\text { total sample } \\
(n=121)\end{array}$ & $\begin{array}{c}\alpha \text { for } \\
\text { males only } \\
(n=49)\end{array}$ & $\begin{array}{c}\alpha \text { 's for } \\
\text { females only } \\
(n=72)\end{array}$ \\
\hline \multicolumn{5}{|l|}{ Male scales } \\
\hline Planful behavior & $\begin{array}{l}10,32,11,20,12 \\
33,34,7,24\end{array}$ & .71 & .70 & .72 \\
\hline $\begin{array}{l}\text { Control of unwanted } \\
\text { thoughts }\end{array}$ & $\begin{array}{l}35,6,21,19,4,9 \\
14,16\end{array}$ & .65 & .48 & .71 \\
\hline Impulse control & $26,27,28,2,25,30$ & .59 & .26 & .69 \\
\hline $\begin{array}{l}\text { Delay of } \\
\text { gratification }\end{array}$ & $29,22,18$ & .75 & .66 & .78 \\
\hline \multicolumn{5}{|l|}{ Female scales } \\
\hline Planful behavior & $\begin{array}{l}30,24,11,1, \\
12,34,32,26,28,7 \\
33,10,2,25,27,20\end{array}$ & .78 & .68 & .82 \\
\hline $\begin{array}{l}\text { Control of unwanted } \\
\text { thoughts }\end{array}$ & $35,6,21,4,16$ & .64 & .51 & .68 \\
\hline $\begin{array}{l}\text { Delay of } \\
\text { gratification }\end{array}$ & $29,22,18,9$ & .69 & .59 & .75 \\
\hline Self-efficacy ${ }^{a}$ & 19,14 & $.51^{* * *}$ & $.44^{* * *}$ & $.56^{* * *}$ \\
\hline \multicolumn{5}{|l|}{ Male/female scales } \\
\hline Mood control & $5,13,17,15$ & .71 & .70 & .72 \\
\hline Pain control $^{a}$ & 23,31 & $.86^{* * * *}$ & $.80^{* * *}$ & $.90^{* * *}$ \\
\hline
\end{tabular}

" Interitem correlations reported for these scales.

${ }^{* * *} p<.001$.

The correlations between the Extrinsic scale of the Religious Orientation scale and all 10 SCS scales were nonsignificant.

In Table 4 it can be seen that 34 out of the 45 intercorrelations among the SCS scales were statistically significant (positive direction). The 11 intercorrelations which were nonsignificant were also all in a positive direction. Of the statistically significant intercorrelations 21 had a $p$ value of .001 or less, 4 had a $p$ value of .01 or less, and 9 had a $p$ value of .05 or less. The 5 largest intercorrelations, however, were caused by overlapping scale items. In general, the rest of the intercorrelations were relatively low which suggests that the SCS scales are quite independent of each other.

\section{DISCUSSION}

The finding that the SCS means for Brigham Young University students were significantly higher than means that have been reported for other English-speaking university students (Redden et al., 1983; Rosenbaum, 1980a) appears to support the construct validity of the SCS. Although 
TABLE 3

Correlations between the Self-Control Schedule Scales and the I-E Scale, Manifest Anxiety Scale (MAS), and Religious Orientation Scale (ROS)

\begin{tabular}{|c|c|c|c|c|}
\hline & \multirow[b]{2}{*}{ I-E scale } & \multirow[b]{2}{*}{ MAS } & \multicolumn{2}{|c|}{ ROS } \\
\hline & & & Intrinsic & Extrinsic \\
\hline \multicolumn{5}{|l|}{ Male scales } \\
\hline Planful behavior & $-.27^{*}$ & -.23 & .20 & .15 \\
\hline $\begin{array}{l}\text { Control of unwanted } \\
\text { thoughts }\end{array}$ & $-.25^{*}$ & $-.56^{* * *}$ & .16 & -.17 \\
\hline Impulse control & $-.36^{* *}$ & $-.51^{* * *}$ & $.34^{*}$ & -.18 \\
\hline Delay of gratification & -.10 & -.15 & .18 & -.21 \\
\hline \multicolumn{5}{|l|}{ Female scales } \\
\hline Planful behavior & $-.35^{* *}$ & $-.45^{* *}$ & $.33^{*}$ & -.03 \\
\hline $\begin{array}{l}\text { Control of unwanted } \\
\text { thoughts }\end{array}$ & $-.29^{*}$ & $-.51^{* * *}$ & .12 & -.11 \\
\hline Delay of gratification & $-.22^{*}$ & -.16 & .20 & -.25 \\
\hline Self-efficacy & .04 & -.22 & .03 & -.02 \\
\hline \multicolumn{5}{|l|}{ Male/female scales } \\
\hline Mood control & $-.28^{*}$ & -.08 & $.32^{*}$ & -.24 \\
\hline Pain control & -.17 & .21 & -.06 & .24 \\
\hline
\end{tabular}

it was not hypothesized that the Brigham Young University students would have unusually high means, it is theoretically understandable why they did. Brigham Young University is a private university, owned by the Church of Jesus Christ of Latter-Day Saints (LDS). Students agree to adhere to an honor code containing numerous ethical and moral guidelines and which requests total abstinance from alcohol, tobacco, illegal drugs, and all sexual relations outside of marriage. The value system of the LDS church is even more demanding than the honor code, and so students, most of whom are LDS, need a high degree of self-control in order to live up to their value system. To help Brigham Young University students in their efforts to adhere to the honor code and their religious values, self-control techniques are frequently shared by religious and school leaders. In such an environment, it is understandable why these students report utilizing self-control techniques so frequently. The high SCS means found for Brigham Young University students, therefore, support the construct validity of the SCS and provide additional normative data about the instrument.

The finding that the correlation between the English versions of the SCS and the I-E scale and the correlation between the Hebrew versions 


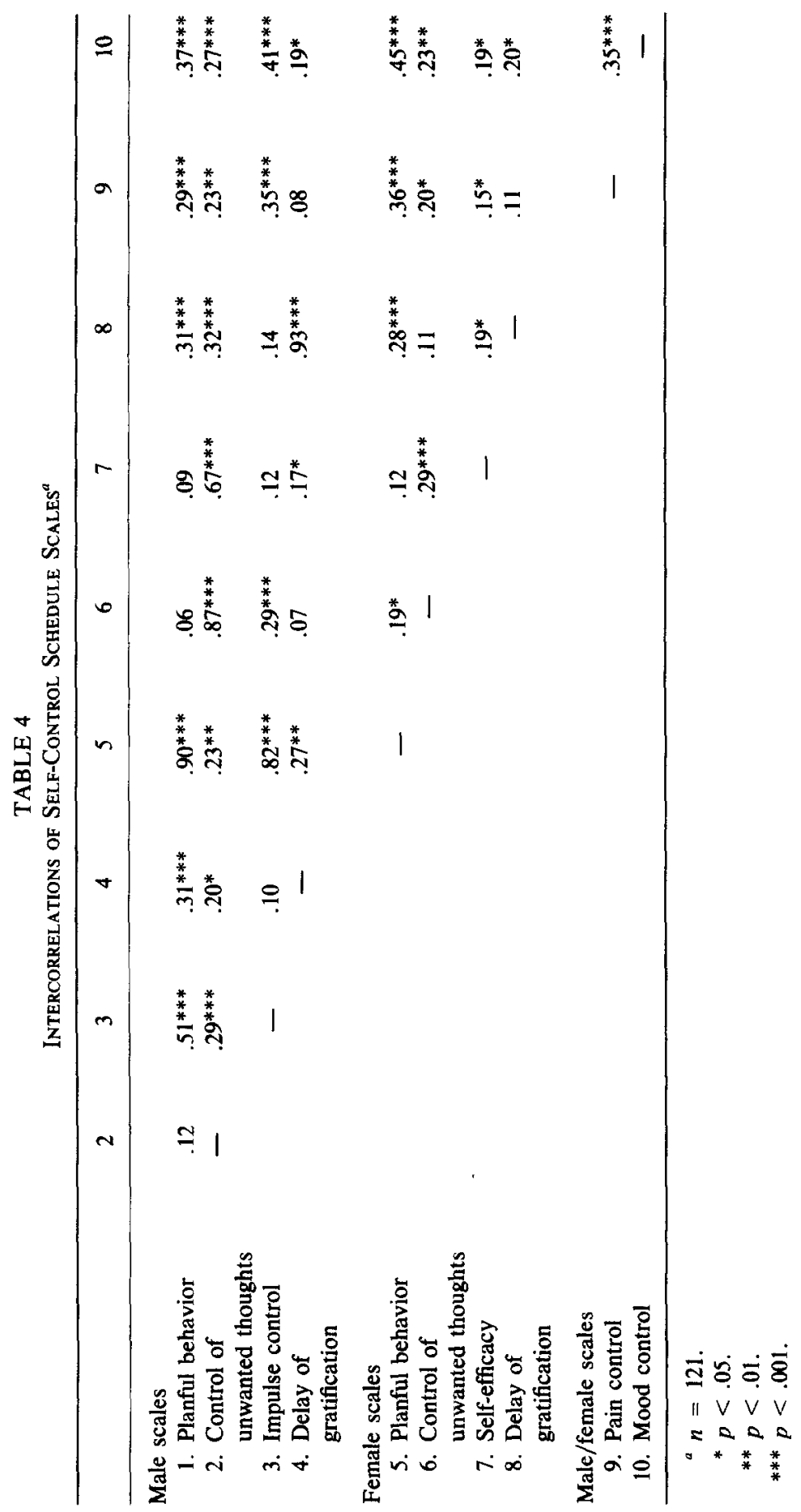


of these instruments were nearly equivalent provides some evidence that the English and Hebrew versions of the SCS were comparable. More evidence is still needed, however, before the comparability of these instruments is definitely established.

The significant correlations between the SCS and the Manifest Anxiety scale and Intrinsic scale of the Religious Orientation scale provide evidence which supports the construct validity of the SCS and further expands the nomological network of the SCS. These correlations suggest that the more a person reports utilizing the self-control techniques described on the SCS, the less anxiety they tend to report and the more people internalize and attempt to live their religion, the more likely it is they will report utilizing the self-control techniques described on the SCS. The negative, but nonsignificant, correlation between the SCS and the Extrinsic scale of the Religious Orientation scale suggests that extrinsic religiousness is not related to how often people report utilizing self-control techniques.

The results of the reliability analyses of the SCS scales, of the Pearson correlation analyses between the SCS scales and the dependent measures, and of the intercorrelations among the SCS scales make several conclusions and recommendations concerning the SCS scales possible. First, the total sample reliability analyses revealed that four SCS scales reached a satisfactory level of reliability for early stage research. However, four of the SCS scales did not reach the minimum reliability of .70 recommended by Nunnally (1978). Researchers interested in using these scales will need to make efforts to increase the reliability of the scales by adding more items to them. Second, the relatively low intercorrelations among the SCS scales provides evidence that the scales are fairly independent of each other and are measuring different constructs. Third, the correlations of the SCS scales with the I-E scale, the Manifest Anxiety scale, and the Religious Orientation scale give some information concerning the location of the SCS variables in the personality space defined by the dependent measures and thus contribute to the construct validation of the SCS scales. More work examining the relationship of the SCS scales with other dependent measures needs to be done, however, to further clarify the meaning of the SCS scales. Finally, although the SCS scales based upon the factors identified by Redden et al. (1983) show promise, their usefulness is limited somewhat because there are separate scales for males and females. Identifying scales which are common to both sexes would increase the practicality of using the SCS as a multidimensional instrument because with common scales for both sexes, the sample size needed in many studies could be smaller than it would otherwise need be, and interpretation of the results would be simplified. Researchers who further examine the dimensionality of the SCS should begin by factor analyzing the SCS with male and female data combined in an effort to identify factors common to both sexes. The fact that no researchers 
besides Redden et al. (1983) have found sex differences on the SCS supports this recommendation.

\section{REFERENCES}

Allport, G. W., \& Ross, J. M. (1967). Personal religious orientation and prejudice. Journal of Personality and Social Psychology, 5, 432-443.

Betz, N. E., \& Weiss, D. J. (1976). Validity of psychological measurements. In B. Bolton (Ed.), Measurement and evaluation in rehabilitation. Baltimore: Univ. Park Press.

Cronbach, L. J. (1951). Coefficient alpha and the internal structure of tests. Psychometrika, 16, 297-334.

Cronbach, L. J., \& Meehl, P. E. (1955). Construct validity in psychological tests. Psychological Bulletin, 52, 281-302.

Donahue, M. J. (1985). Intrinsic and extrinsic religiousness: Review and meta-analysis. Journal of Personality and Social Psychology, 48, 400-419.

Goldfried, M. R., \& Merbaum, M. M. (Eds.) (1973). Behavior change through self-control. New York: Holt, Rinehart \& Winston.

Hall, S. M. (1980). Self-management and therapeutic maintenance: Theory and research. In P. Karoly \& J. J. Steffen (Eds.), Improving the long-term effects of psychotherapy: Models of durable outcome. New York: Gardner.

Jeffrey, D. B., \& Berger, L. H. (1982). A self-environmental systems model. In K. R. Blankstein \& J. Polivy (Eds.), Self-control and self-modification of emotional behavior (Vol. 7). New York: Plenum.

Kanfer, F. H. (1977). The many faces of self-control, or behavior modification changes its focus. In R. B. Stuart (Ed.), Behavioral self-management: Strategies, techniques, and outcome. New York: Brunner/Mazel.

Kanfer, F. H. (1980). Self-management methods. In F. H. Kanfer \& A. P. Goldstein (Eds.), Helping people change: A textbook of methods (2nd ed.). New York: Pergamon.

Karoly, P., \& Kanfer, F. H. (Eds.) (1982). Self-management and behavior change: From theory to practice. New York: Pergamon.

Meichenbaum, D. (1975). Toward a cognitive theory of self-control. In G. Schwartz \& D. Shapiro (Eds.), Consciousness and self-regulation: Advances in research. New York: Plenum.

Nunnally, J. C. (1978). Psychometric theory (2nd ed.). New York: McGraw-Hill.

Redden, E. M., Tucker, R. K., \& Young, L. (1983). Psychometric properties of the Rosenbaum schedule for assessing self-control. The Psychological Record, 33, 77-86.

Rosenbaum, M. (1980a). A schedule for assessing self-control behaviors: Preliminary findings. Behavior Therapy, 11, 109-121.

Rosenbaum, M. (1980b). Individual differences in self-control behaviors and tolerance of painful stimulation. Journal of Abnormal Psychology, 89, 581-590.

Rosenbaum, M., \& Rolnick, A. (1983). Self-control behaviors and coping with seasickness. Cognitive Therapy and Research, 7, 93-98.

Rotter, J. B. (1966). Generalized expectancies for internal versus external control of reinforcement. Psychological Monographs, 80, (No. 1).

Rotter, J. B. (1975). Some problems and misconceptions related to the construct of internal versus external control of reinforcement. Journal of Consulting and Clinical Psychology, $43,56-67$.

Taylor, J. A. (1953). A personality scale of manifest anxiety. The Journal of Abnormal and Social Psychology, 48, 285-290.

Taylor, J. A. (1956). Drive theory and manifest anxiety. Psychological Bulletin, 53, 303 320.

Thoresen, C. E., \& Mahoney, M. J. (1974). Behavioral self-control. New York: Holt, Rinehart \& Winston. 